\title{
Immediate Loading with Intraoral Welding for Improved Implant Stability during Healing
}

\author{
${ }^{1}$ Silvano Umberto Tramonte, ${ }^{2}$ Aldo Daniele Dominici, ${ }^{3}$ Gregori M Kurtzman \\ ${ }^{1}$ Dental Surgeon, Professor, Electrowelded Implantology Training Course \\ University G D'Annunzio of Chieti-Pescara, Chieti, Italy \\ ${ }^{2}$ Dental Surgeon, Milano, Italy \\ ${ }^{3}$ General Dental Practitioner, Silver Spring, Maryland, USA
}

Correspondence: Silvano Umberto Tramonte, Dental Surgeon, Centro Implantologico Tramonte-Piazza Castello 5, 20121

Milan, Italy, e-mail: tramonte@ tramonte.com

\section{ABSTRACT}

Purpose: A clinical case is presented demonstrating the utilization of intraoral welding (syncrystallizer) to stabilize immediate one-piece implants during osteointegration for a fixed full-arch upper and lower rehabilitation with flapless surgical approach.

Materials and methods: The surgical and prosthetic technique including postextraction placement of one-piece implants, modification of the implants intraorally for prosthetic angulation, and the method of initial bracing the implants, is described. The procedure has been subdivided by arch, with each arch being treated in a similar manner during a single surgical appointment for the full mouth implant treatment.

Outcome: No complications are reported, and no implant has been lost one and a half years following surgical placement and restoration The patient maintains appropriate oral hygiene and is pleased with the functional and esthetic results. The radiographs demonstrate maintenance of the osseous crestal levels with no peri-implant bone loss.

Conclusions: The technique has demonstrated an effective aid for immediate implant stabilization allowing immediate loading without hampering the osteointegration process.

Keywords: Electrowelded implantology, Syncrystallizer, Immediate loading, Intraoral welding, Flapless surgery.

\section{INTRODUCTION}

Implant initial stabilization has become an unsurpassed advantage with respect to rehabilitation with individual implants, because it allows a more balanced dissipation of mastication loads and, as a consequence, a lower risk of implant loss during and after osteointegration can be expected. ${ }^{1-12}$

For this purpose, the most frequently used methods are the production of a cast bar to be fastened to the implants with screws or with the placement of a metal reinforced screwed/cemented temporary prosthesis. ${ }^{13-25}$ An interesting alternative is given by the intraoral welder. The technique allows the practitioner to effectively splint all of the implant heads in the arch by welding a titanium bar intraorally, capturing them in a passive state. The process used by this welder consists of a sharing of atoms to form a crystallized lattice in the junction area between the bar and implant. Such junction is generated by an instantaneous flow of electrons through the two surfaces. ${ }^{2-10}$ After an adequate healing period to allow osteointegration to occur, the bar is removed by sectioning the bar and polishing the areas of the welds on the implant heads. ${ }^{26-49}$

\section{CLINICAL CASE}

The patient DF, a male who is a current smoker, sought care related to poor oral hygiene, with high mobility of the remaining teeth. Periodontal involvement with mobility was noted on all remaining teeth with the exception of the lower right and left canines and maxillary left second molar, which had no mobility and were determined to be periodontally stable. A long span, five unit fixed bridge was present in the maxillary posterior being supported by two abutment teeth with periodontal bone loss noted (Figs 1 to 3).

Following clinical and radiographic examination (Fig. 4), serological tests revealed serious hypertrigliceridemia and hypercholesterolemia. The patient had been advised of the need to perform horizontal bone augmentations and sinus lift interventions to permit implant placement.

The patient declined the grafting that had been recommended and inquired as to what other options were available. The use of Italian school implants and techniques was discussed and the patient selected to pursue that treatment option. These techniques and implants allow placement respecting the available bone and anatomy present in the individual patient. According to patient's requests, an upper and lower full-arch implant rehabilitation was performed, with mixed support (implants and remaining natural teeth) and immediate loading of fixed prosthesis.

Under strict control of a presurgery CAT scan (Figs 5 and 6), the teeth deemed poor prognosis were extracted, and Tramonte one-piece implants (Società di Scienza 


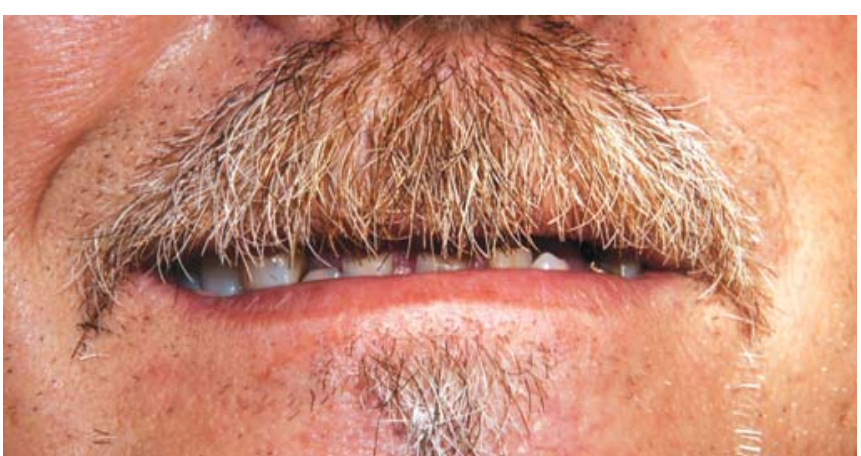

Fig. 1: Patient as he presented demonstrating minimal tooth visibility and poor esthetics

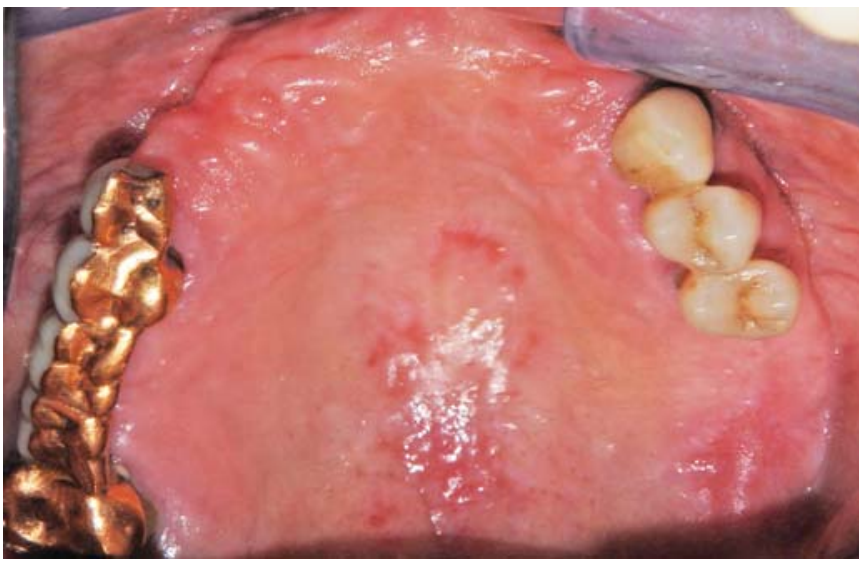

Fig. 2: Maxillary arch demonstrating the remaining dentition and failing restorative dentistry

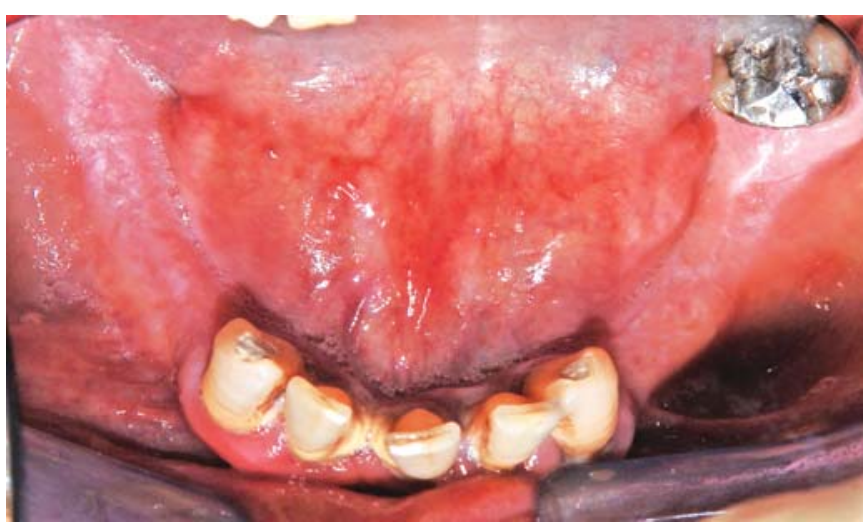

Fig. 3: Mandibular arch demonstrating narrow width of ridge in the edentulous posterior with periodontal involvement of the lower anterior and a large failing restoration on the remaining molar

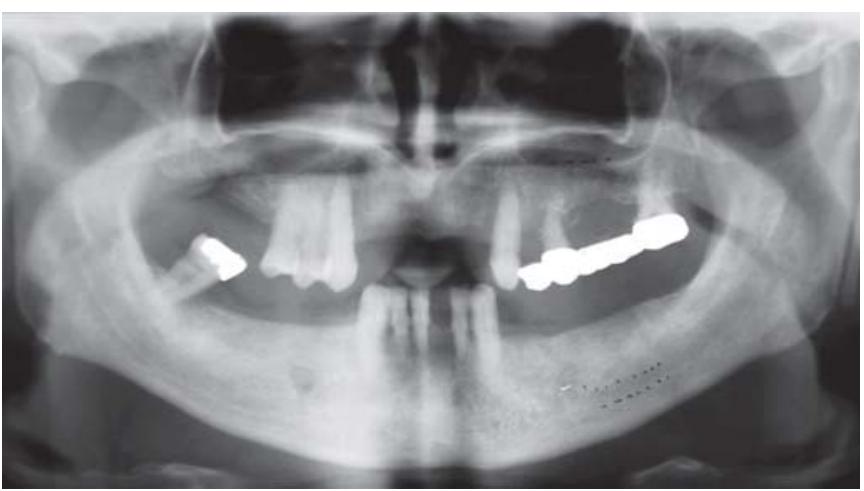

Fig. 4: Initial panoramic radiograph
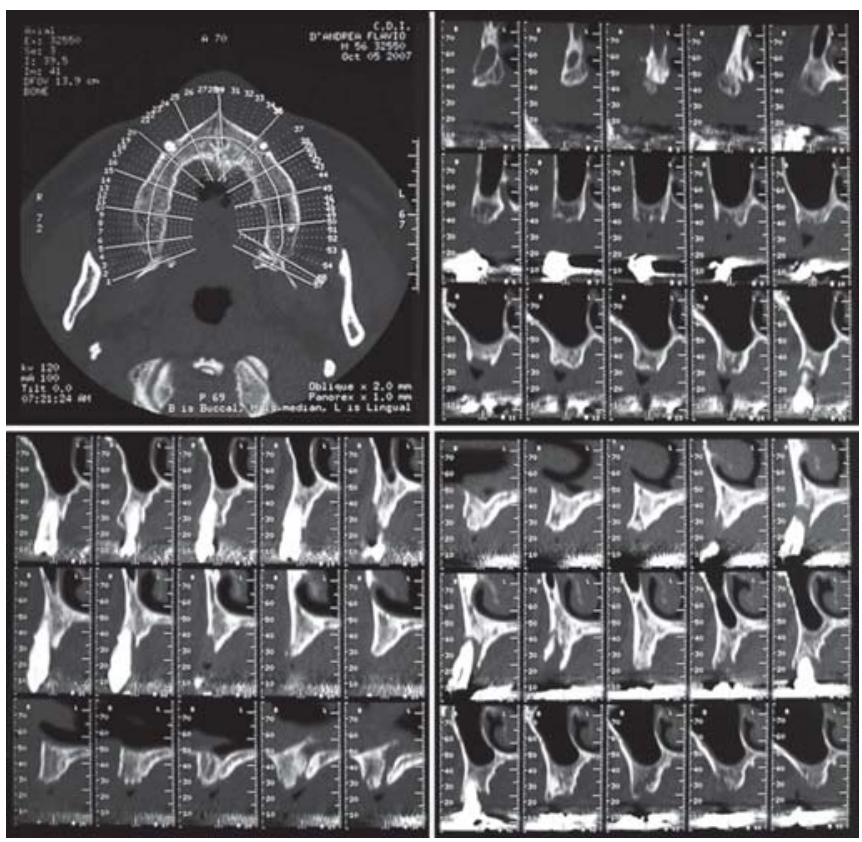

Fig. 5: CAT scan demonstrating the available bone present in the maxilla

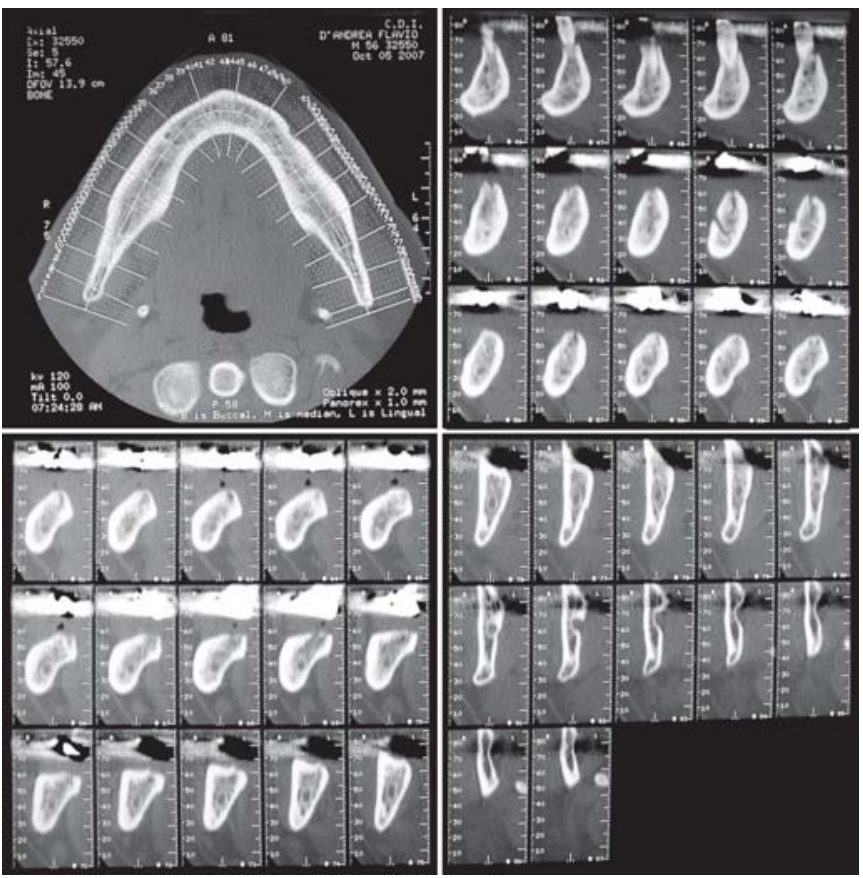

Fig. 6: CAT scan demonstrating the available bone present in the mandible

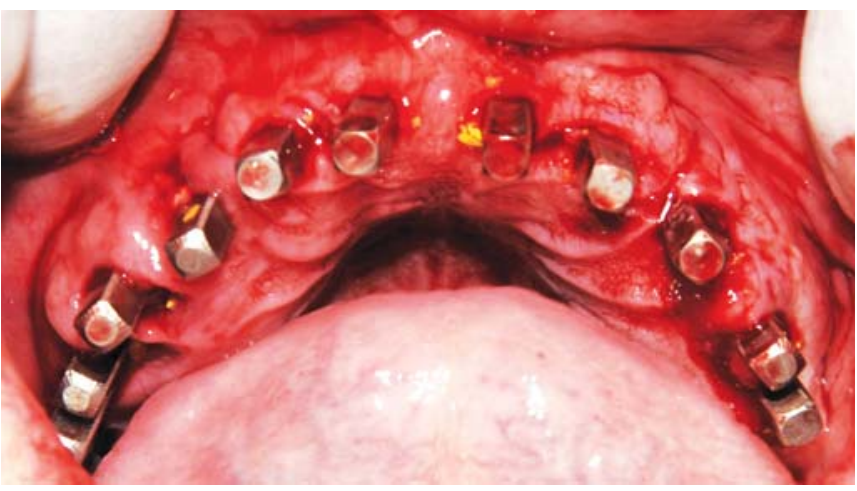

Fig. 7: Maxillary arch following placement of Tramonte one-piece implants 
Tramonte, Milan, Italy) were placed, both in extraction sites and edentulous area in a flapless approach. The bilateral mandibular cuspids were endodontically treated and prepared to accept crowns (Figs 7 and 8).

The number of implants placed was equal to the number of teeth to be rehabilitated, or greater in the case of the posterior sectors, where every prosthetic element was supported by one or two implants. This was decided to guarantee a load distribution on the greatest possible number of implant pillars. In fact, in these sectors quality and quantity of available bone would have made it impractical to place narrow thread, nonsplinted implants.

The planned roundhouse fixed prosthesis included 13 units for the maxillary arch and 14 for the mandibular arch. During surgery, because of insufficient primary stability, it was decided to load with prosthetics the implant fixtures in posterior maxillary right, only after sufficient trabecular densification had been achieved. Until that time, these implants would contribute to the stability of rest of the arch by being connected to the welded bars and masticatory load would be minimized on these fixtures in the interim period. But the necessary functional stimuli for the maturation of the surrounding bone tissue would be placed on these fixtures via the splinting with the welded bar.

The implant insertion point into the osseous bed has been defined according to the guidelines of implantology guided by the prosthesis to be placed. This would ensure that every implant post would correspond to a prosthetic unit being rehabilitated.

The angle of implant insertion followed principles of anatomically guided implantology. According to these principles, the implant fixtures are inserted on the axes that best exploits the sites with greatest bone volume. This results in the directions of the heads being nonparallel to each other. The benefit of this approach is that it creates the largest possible support base and better dissipation of lateral loads. Due to the composition of these titanium implants and their narrow cervical diameter, the heads can be paralleled by gentle bending of the head while bracing the bone at the cervical.

The implants used in the case presented were Tramonte and transmucosal Garbaccio (Società di Scienza Tramonte, Milan, Italy). The surgery was performed with a flapless technique. The sutures were only placed in the postextraction sites to speed up healing and facilitate the formation of a papilla.

An instrumental control of the primary stability of all the implants was performed with the aid of a Periotest (Modautal, Germany). Subsequently, the implants were splinted directly in the mouth by welding a lingual bar, made of grade 2 titanium, in a $1.2 \mathrm{~mm}$ diameter at a level coronal to the gingival tissue. A buccal crossbar was added to further splint and stabilize the posterior right fixtures to compensate for the lack of primary stability (Figs 9 and 10).

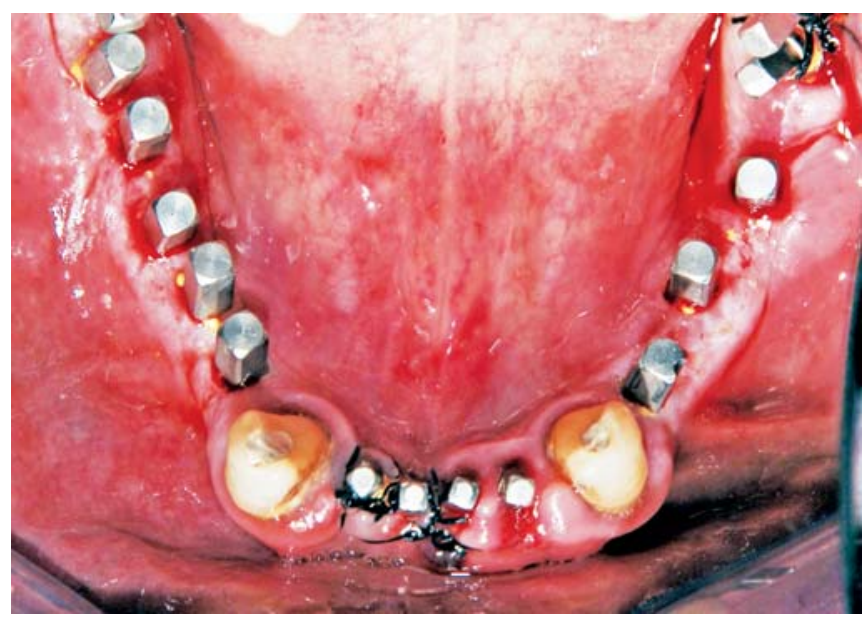

Fig. 8: Mandibular arch following placement of Tramonte one-piece implants and endodontic treatment of the bilateral cuspids and crown preparation of these remaining teeth

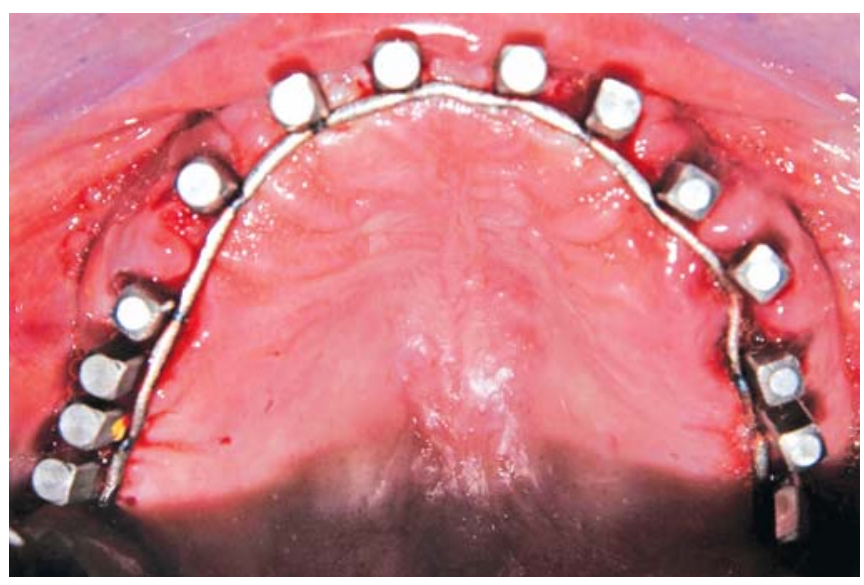

Fig. 9: Titanium bar shown welded to the maxillary implant fixtures

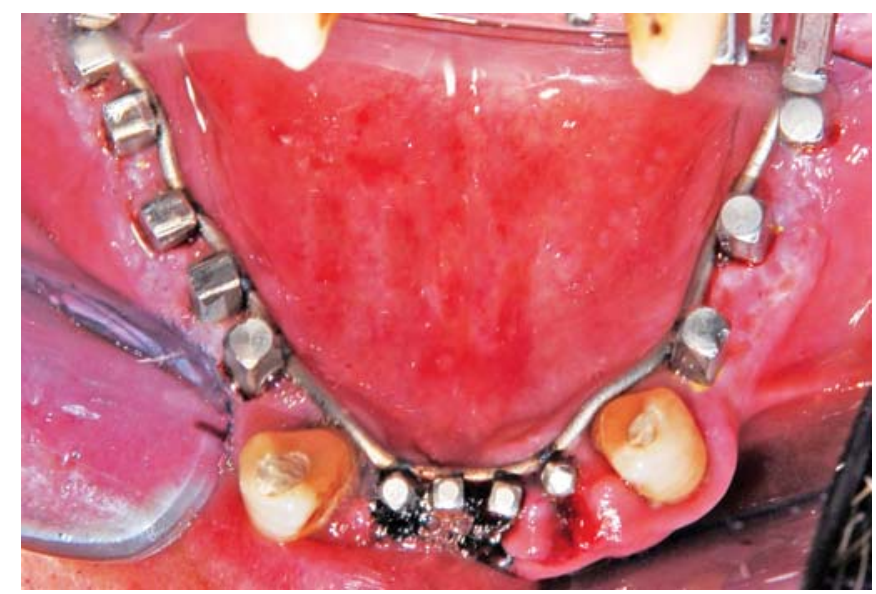

Fig. 10: Titanium bar shown welded to the mandibular implant fixtures circumventing the remaining cuspids

Immediately following surgical placement and intraoral welding, a provisional prosthesis was tried in, after it was prepared by the laboratory technician based on presurgery impressions and articulation of the casts. The provisional prosthesis was relined with tooth colored acrylic resin (Paladur-Heraeus Kulzer, Hanu, Germany) by a direct 


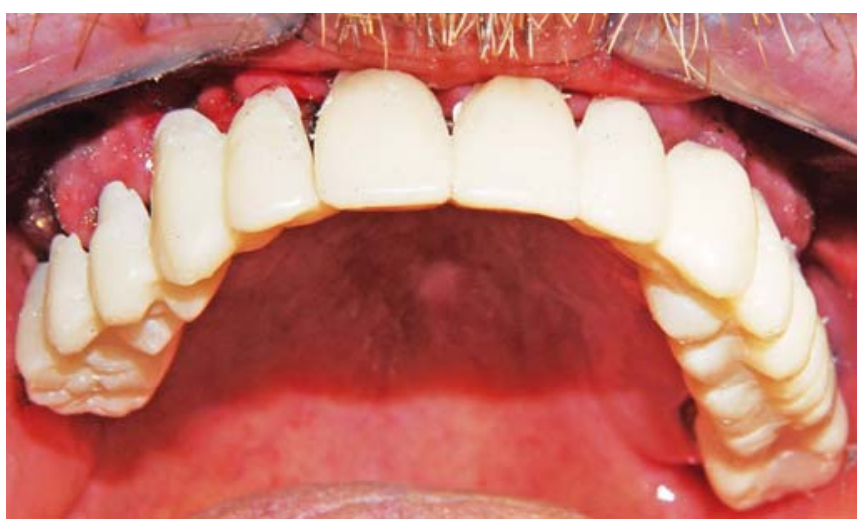

Fig. 11: Maxillary provisional prosthesis temporarily cemented upon the splinted implants

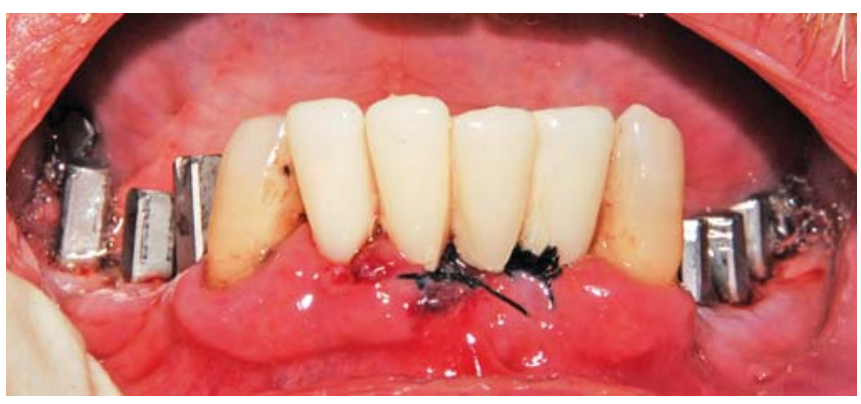

Fig. 12: Provisional restorations placed upon the mandibular anterior implants

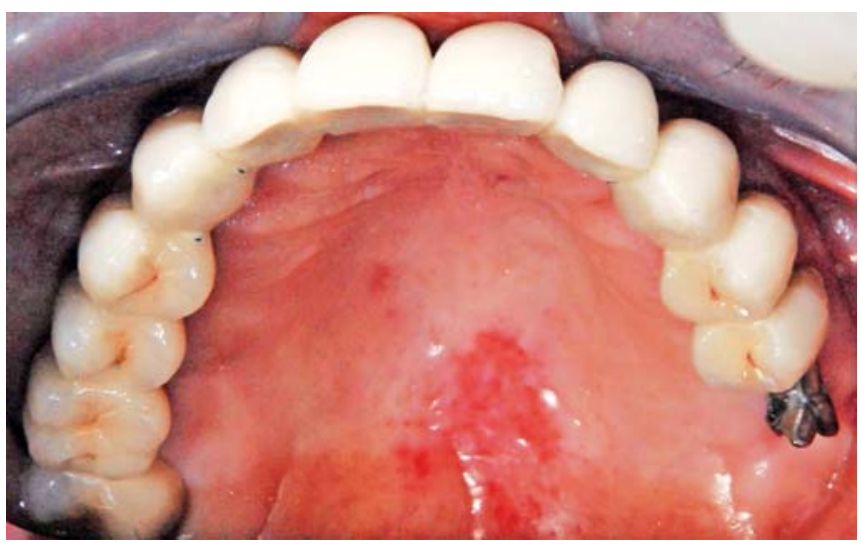

Fig. 13: The final maxillary porcelain fused to metal prosthesis with cross-arch stabilization. Note that the fixtures in the posterior right have not received the final prosthesis at this time allowing them to further integrate

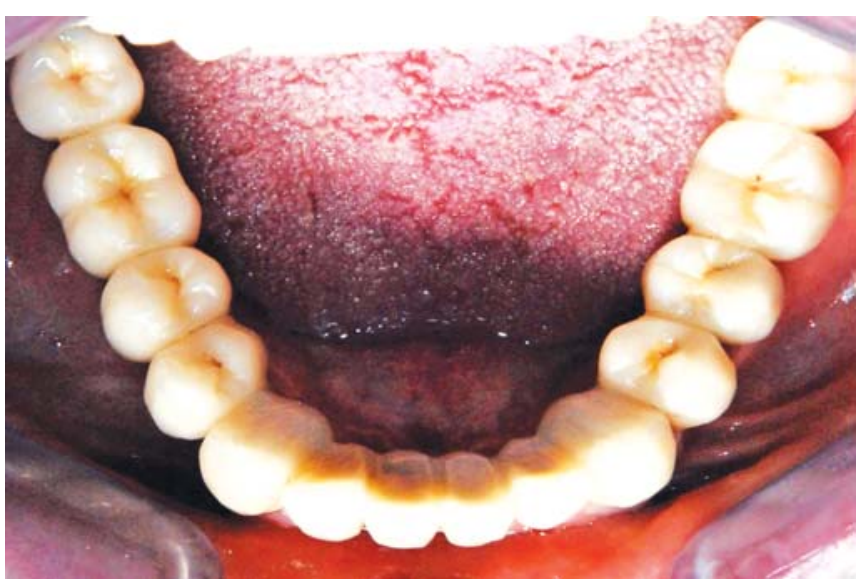

Fig. 14: Mandibular final porcelain fused to metal prosthesis splinting the entire arch technique. Following setting of the provisional resin and polishing the margins, the restorations were temporarily luted, and occlusion was checked in all positions and a balanced occlusion was developed (Figs 11 and 12). Postoperatively, the patient was given $400 \mathrm{mg}$ of ibuprofen and an ice pack, to reduce any postoperative edema.

Following three months of postsurgical healing, unlike the two months prescribed by the protocol, the bars splinting all the implants were removed to test the implant osteointegration by using a Periotest. In spite of the fact that osseointegration had been documented on all the fixtures, it was decided to reposition the bars in consideration of the patient's general clinical condition and continued smoking. The final porcelain fused to metal roundhouse prosthesis was fabricated and cemented in place, with the exception of restoration of the most posterior maxillary right fixtures which had been manufactured and welded to the prosthesis 12 months after implant placement (Figs 13 to 16).

The patient was followed at regular intervals. Soft tissue demonstrated a lack of inflammation and bleeding and by all measures was healthy periodontally (Fig. 17). At this time a follow-up radiograph was taken 6 months postrestoration of the mandibular arch and 3 months on the maxillary arch to verify bone levels (Fig. 18). At 18 months postsurgical placement a panoramic radiograph was taken and bone levels remained consistent with the prior radiographs with no loss of crestal bone and soft tissue remained healthy (Fig. 19).

\section{CONCLUSION}

The rehabilitation of the clinical case discusses herein, highlights how intraoral welding, a technique used clinically for more than 30 years, is an effective and predictable therapeutic choice in cases of immediate loading implantology and advanced implantology.

The creation of a solid implant structure that is independent from the prosthesis, to support axial and lateral loads, has been shown to be able to withstand masticatory forces by dissipating them over larger areas providing greater bone support. This rehabilitation technique, documented in the literature initially in 1982, is advantageous in terms of time elapsed with respect to the use of screw-retained bars, and the biological costs associated with extensive grafting needed in similar cases. This also reduces the risk of loss of stability with respect to the use of cemented temporary prostheses.

In advanced implantology, where there is the need to rehabilitate the maxillary arch where osseous support is limited and the great elasticity of these structures generates imbalances with respect to the more compact areas. This technique allows reconstruction of a more rigid, selfsupporting implant structure that is independent of the 


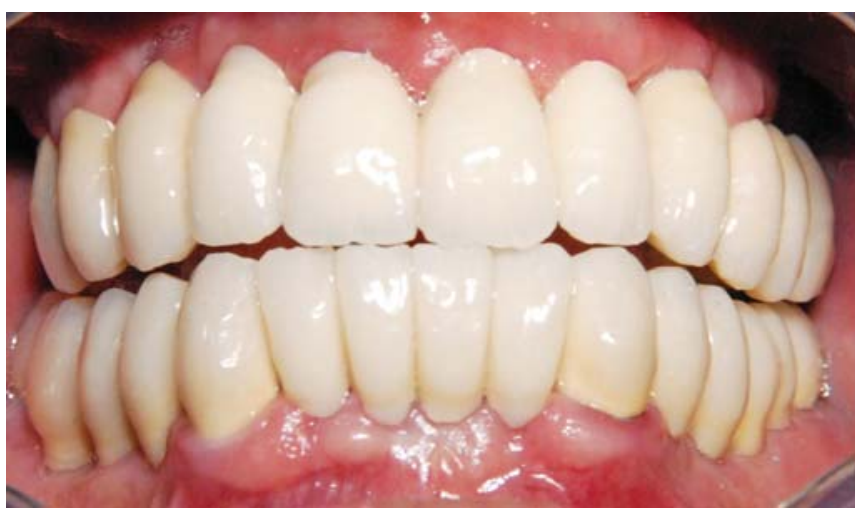

Fig. 15: Buccal view of the final porcelain fused to metal prosthesis in the maxillary and mandibular arches

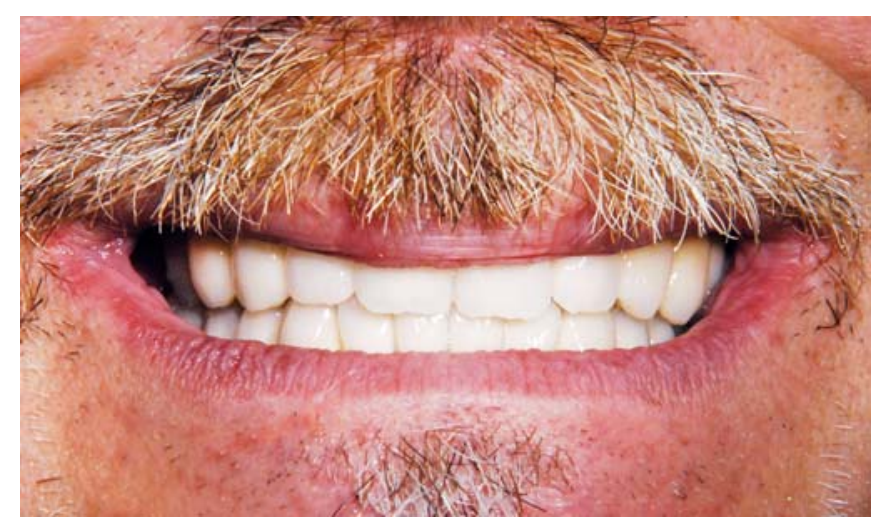

Fig. 16: The patient showing his new smile following insertion of the final porcelain fused to metal prosthetics

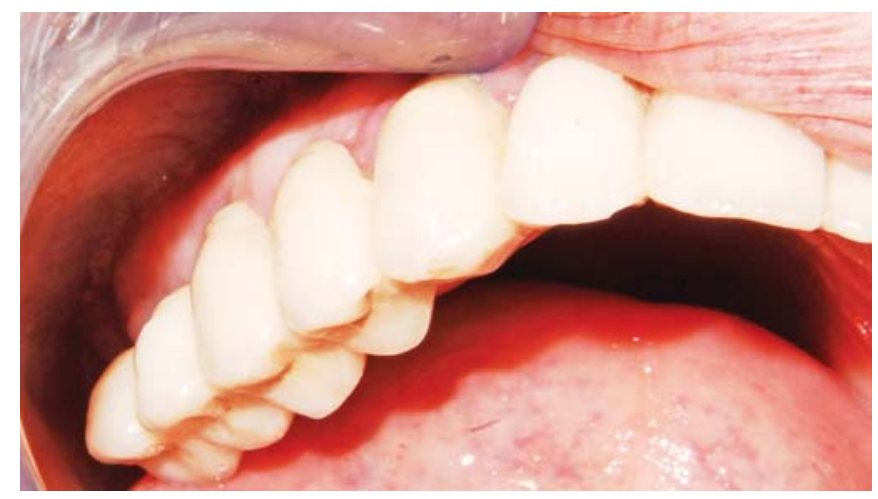

Fig. 17: Soft tissue shown in the maxillary right posterior at 18 months postsurgery, demonstrating health periodontal tissues

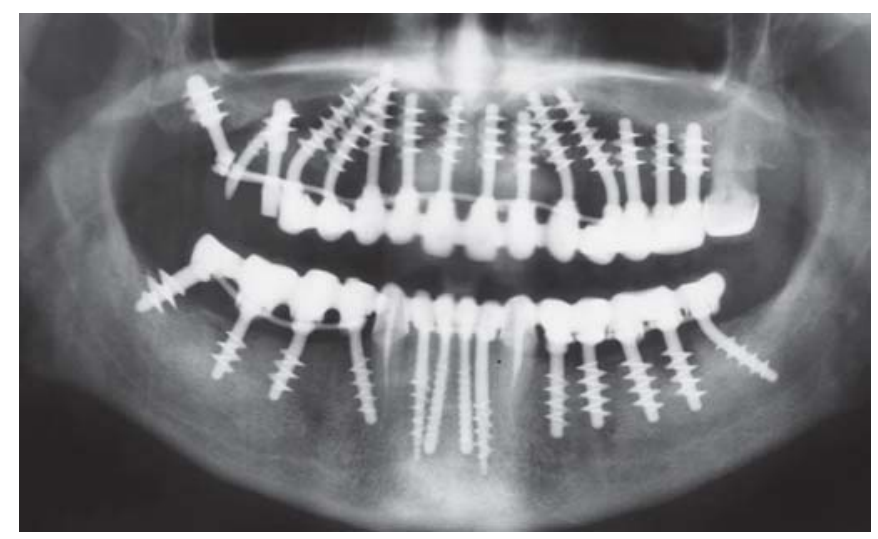

Fig. 18: Panoramic radiograph 6 months in the mandible and 3 months in the maxilla following implant placement

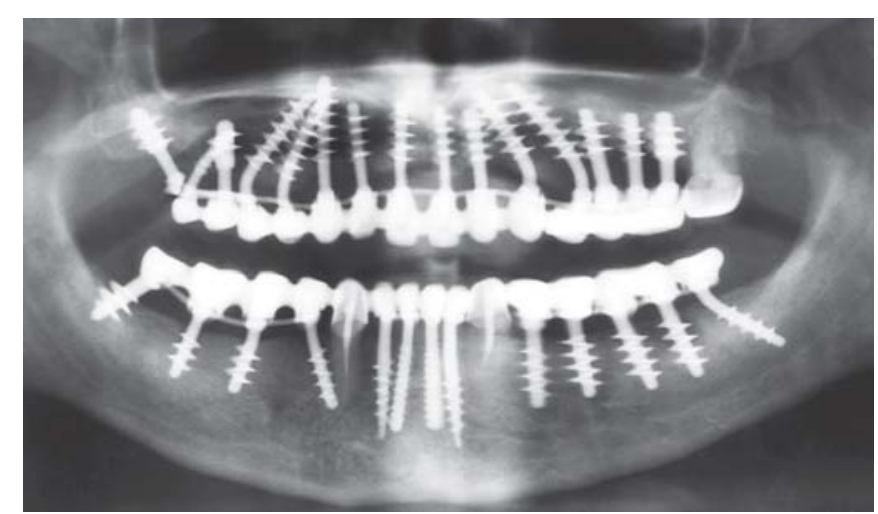

Fig. 19: Panoramic radiograph 18 months postsurgical placement of the immediate loaded and welded implants

prostheses. The authors agree that further studies are necessary to document an effectiveness that has been proven, to delimit precisely its uses and limitations.

\section{REFERENCES}

1. Degidi M, Gehrke P, Spanel A, Piattelli A. Syncrystallization: A technique for temporization of immediately loaded implants with metal-reinforced acrylic resin restorations. Clin Implant Dent Relat Res 2006;8(3):123-34.

2. Gehrke P. The syncrystallization technique: Expediting rigid splinting of immediately loaded implants. Dent Implantol Update. Mar 2006;17(3):17-23.

3. Mondani PL, Mondani PM. The Pierluigi Mondani intraoral electric welder: Principles of development and explanation of the welder using syncrystallization. Riv Odontostomatol Implantoprotesi Jul-Aug 1982;(4):28-32.

4. Degidi M, Nardi D, Piattelli A. Immediate rehabilitation of the edentulous mandible with a definitive prosthesis supported by an intraorally welded titanium bar. Int J Oral Maxillofac Implants Mar-Apr 2009;24(2):342-47.

5. Degidi M, Nardi D, Piattelli A. Immediate loading of the edentulous maxilla with a final restoration supported by an intraoral welded titanium bar: A case series of 20 consecutive cases. J Periodontol Nov 2008;79(11):2207-13.

6. Hruska A, Borelli P, Bordanaro AC, Marzaduri E, Hruska KL. Immediate loading implants: A clinical report of 1301 implants. J Oral Implantol 2002;28(4):200-09.

7. Hruska AR, Borelli P. Intraoral welding of implants for an immediate load with overdentures. J Oral Implantol 1993;19(1):34-38.

8. Hruska AR, Borelli P. Quality criteria for pure titanium casting, laboratory soldering, intraoral welding, and a device to aid in making uncontaminated castings. J Prosthet Dent Oct 1991;66(4):561-65.

9. Hruska AR. Welding implants in the mouth. J Oral Implantol 1989;15(3):198-203.

10. Hruska AR, Zappe W. Intraoral welding of pure titanium. Quintessence Int Oct 1987;18(10):683-88.

11. Li H, Xiao M, Zhao Y. Dental welding titanium and its clinical usage. Sheng Wu Yi Xue Gong Cheng Xue Za Zhi Sep 1998;15(3):303-5, 310. 
12. Haney SC, Meiers JC. In vitro study of intraoral welding procedures for pure titanium. Quintessence Int Dec 1996;27(12):841-47.

13. Brànemark PI, Breine U, Adell R, Hanson BO, Linstrtim J, Ohlsson A. Intraosseous anchorage of dental prosthesis (I). Experimental studies. Scandinavian Journal of Plastic Reconstructive Surgery 1969;3:81-100.

14. Albrektsson T, Brànemark PI, Hansson HA, Lindstrom. Osseointegrated titanium implants: Requirements for ensuring a long-lasting, direct bone-to-implant anchorage in man. Acta Orthopaedica Scandinavica 1981;52:155-70.

15. Brànemark PI. Osteointegration and its theoretical background. Journal of Prosthetic Dentistry 1983;50:399-410.

16. Donath K, Laass M, Gunzl HJ. The histopathology of different foreign-body reactions to oral soft tissue and bone tissue. Virchows Archiv A Pathol Anat 1992;420:131-37.

17. Ledermann PD. The New Ledermann Screw (Artide in German). Die Quintessenz 1988;5:1-17.

18. Schnitman PA, Weihrle PS, Rubenstein JE. Immediate fixed interim prostheses supported by two-stage threaded implants: Methodology and results. Oral Implantol 1990;16:96-105.

19. Salama H, Rose LF, Salama M, Betts NJ. Immediate loading of bilaterally splinted titanium root-form implants in fixed prosthodontics. A technique re-examined: Two case reports. Int J Periodont Rest Dent 1995;15:345-61.

20. Ledermann PD. More than 20 years of experience with immediate loading of implant borne cantilever prostheses in the interforaminal region. Zeitschrift kir Zahnàrztliche Implantologie 1996;12:123-36.

21. Chiapasco M, Gatti C, Rossi E, Haefliger W, Markwalder TH. Implant-retained mandibular overdentures with immediate loading: A retrospective multicenter study on 226 consecutive cases. Clin Oral Impl Res 1997;8:48-57.

22. Tarnow DP, Emtiaz S, Classi A. Immediate loading of threaded implants at stage 1 surgery in edentulous arches: Ten consecutive case reports with 1- to 5-year data. Int J Oral Maxillofac Implants 1997;12:319-24.

23. Schnitman PA, Whrle PS, Rubenstein JE, DaSilva JD, Wang $\mathrm{NH}$. Ten-year results for Branemark implants immediately loaded with fixed prostheses at implant placement. Int J Oral Maxillofac Implants 1997;12:495-503.

24. Balshi TJ, Wolfinger GJ. Immediate loading of Brànemark implants in edentulous mandibles: A preliminary report. Implant Dent 1997;6:83-88.

25. Whórle PS. Single-tooth replacement in the esthetic zone with immediate provisionalization: Fourteen consecutive case reports. Pract Periodont Aesthet Dent 1998;10:1107-14.

26. Piattelli A, Corigliano M, Scarano A, Costigliola G, Paolantonio M. Immediate loading of titanium plasma-sprayed implants: A pilot study in monkeys. J Periodontol 1998;69: 321-27.

27. Misch CE. Non-functional immediate teeth in partially edentulous patients: A pilot study of 10 consecutive cases using the Maestro dental implant system. Compendium 1998;19: 25-36.

28. Jaffin RA, Kumar A, Berman CL. Immediate loading of implants in partially edentulous jaws: A series of 27 case reports. J Periodontol 2000;71:833-38.
29. Horiuchi K, Uchida H,Yamamoto K, Sugimura M. Immediate loading of Branemark system implants following placement in edentulous patients: A clinical report. Int J Oral Maxillofac Implants 2000;15:824-30.

30. Rocci A, Martignoni M, GottlowJ, Rangert B. Immediate function of single and partial reconstructions in the maxilla using MK IV fixtures: A retrospective analysis. Applied Osteointegration Research 2001;2:22-26.

31. Cooper LF, Rahman A, Moriarty J, Chaffee N, Sacco D. Immediate mandibular rehabilitation with endo-osseous implants: Simultaneous extraction, implant placement and loading. Ind Oral Maxillofac Implants 2002;17:517-25.

32. Degidi M, Piattelli A. Immediate functional and non-functional loading of dental implants: A 2 to 60 months follow-up study of 646 titanium implants. J Periodontol 2003;74:225-41.

33. Degidi M, Piattelli A, Felice P, Carinci F. Immediate functional loading of edentulous maxilla: A 5-year retrospective study of 388 titanium implants. J Periodontol Jun 2005;76(6):1016-24.

34. Degidi M, Piattelli A. Comparative analysis study of 702 dental implants subjected to immediate functional loading and immediate non-functional loading to traditional healing periods with a follow-up of up to 24 months. Int J Oral Maxillofac Implants 2005;20:99-107.

35. Degidi M, Piattelli A. 7-year follow-up of 93 immediately loaded titanium dental implants. J Oral Implanto 2005;31(1):25-31.

36. Ivanoff CJ, Sennerby L, Lekholm U. Influence of initial implant mobility on the integration of titanium implants: An experimental study in rabbits. Clinical Oral Implants Research 1996;7: 120-27.

37. Hoshaw SJ, Brunski JB, Cochran GVB. Mechanical loading of Brànemark implants affects interfacial bone modeling and remodeling. IntJ Oral Maxillofac Implants 1994;9:345-60.

38. Nkenke E, Lehner B, Weinzierl K, Thams U, Neugebauer J, Steveling H, Radespiel-Trager M, Neukam FW. Bone contact, growth, and density around immediately loaded implants in the mandible of mini pigs. Clin Oral Hp Res 2003;14: 312-21.

39. Frost HM. The role of changes in mechanical usage set points in the pathogenesis of osteoporosis. J Bone Minerai Res 1992; 7:253-61

40. Piattelli A, Ruggeri A, Trisi P, Romasco N, Franchi M. A histologic and histomorphometric study of the bone reactions to non-submerged unloaded and loaded single implants in monkeys. J Oral Implantol 1993;19:314-20.

41. Piattelli A, Trisi P, Romasco N, Emanuelli M. Histological analysis of a screw implant retrieved from man: Influence of early loading and primary stability. J Oral Implantol 1993;19:303-06.

42. Piattelli A, Corigliano M, Scarano A. Microscopical observations of the osseous responses in early loaded human titanium implants: A report of two cases. Biomaterials 1996;17: 1333-37.

43. Piattelli A, Corigliano M, Scarano A, Quaranta M. Bone reactions to early occlusal loading of two -stage titanium plasmasprayed implants: A pilot study in monkeys. Int J Periodont Rest Dent 1997;17:163-69.

44. Piattelli A, Scarano A, Paolantonio M. Immediately loaded screw implant removed for fracture after a 15 -year loading period: 
Histological and histochemical analysis. J Oral Implantol 1997;23:75-79.

45. Degidi M, Sca rano A, Piattelli M, Perrotti V, Piattelli A. Bone remodeling in immediately loaded and unloaded titanium dental implants: A histologic and histomorphometric study in humans. J Oral Implantol 2005;31(1)18-24.

46. Brunski JB, Moccia AF Jr, Pollack SR, Korostoff E, Trachtenberg DI. The influence of functional use of endossous dental implants on the tissue-implant interface. Histological aspects. J Dental Res 1979;58:1953-69.
47. Brunski JB. Influence of biomechanical factors at the bonebiomaterial interface. In: Davies JE (Ed). The Bone-Biomaterial Interface. Toronto: Toronto University Press 1991:391-405.

48. Brunski JB. Forces on dental implants and interfacial stress transfer. In: Laney WR, Tolman DE (Eds). Tissue Integration in Oral, Orthopaedic and Maxillofacial Reconstruction. Chicago: Quintessence 1992:108-24.

49. Brunski JB. Avoiding pitfalls in overloading and micromotions of intraosseous implants (Interview). Dent Implantol Update 1993;4(10):77-81. 